\title{
İki hidrodinamik programın karşılaştırılması
}

\author{
Elif OĞUZ $\mathbf{Z}^{1,2, *}$ \\ ${ }^{1}$ Orta Doğu Teknik Üniversitesi, Inşaat Mühendisliği Bölümü Hidrolik Laboratuvart \\ ${ }^{2}$ Orta Doğu Teknik Üniversitesi, Rüzgar Enerji Teknolojileri Araştırma ve Uygulama Merkezi \\ (RÜZGEM) \\ Geliş Tarihi (Received Date): 26.02.2019 \\ Kabul Tarihi (Accepted Date): 13.09.2019
}

\begin{abstract}
Özet
Açık deniz yapılarının zaman ve maliyet kisıtlamaları sebebiyle, tasarımın ilk aşamasında sayısal metotlara ihtiyaç duyulur. Modellemenin güvenilir şekilde yapılıp yapılamayacağını anlamak için tasarıma başlamadan önce kıyaslama çalışmaları yürütülmektedir. Karşılaştırma çalışması için, genellikle, üzerinde çalışılan tasarıma geometrik olarak en yakın yapı seçilir. Geometrik benzerliğin yanı sıra seçilecek karşılaşıtırma çalışmasının gerekli verilerine rahatlıkla ulaşılıp ulaşılamayacă̆ önemlidir. Sonrasında, yayınlanmış olan bu karşılaştırma çalışması yeniden modellenip sonuçları ile kıyaslanır. Seçilen yazılımlar ya da açık kaynaklı kodlar bazı teorik kabullere ve bazen basitleştirmelere dayandığından, çoğu zaman araştırmacılar farklı sayısal programlar kullanmayı tercih ederler. Bu çalışmada açıkdeniz yapılarının hidrodinamik analizinde yaygin olarak kullanılan MIT tarafindan geliştirilmiş WAMIT programı ile Fransa'daki Nantes laboratuvarındaki araştırmacılar tarafindan geliştirilen açık kaynaklı kod NEMOH kullanılarak silindir bir yapı modellenmiş ve her iki yazılımın avantajları ile dezavantajları tartışılmıştır.
\end{abstract}

Anahtar kelimeler: Hidrodinamik, sayısal modelleme, açık kaynaklı kod.

\section{A Comparison of two hydrodynamic programmes}

\begin{abstract}
Due to time and cost restraints the first stage of design of offshore structures requires a numerical approach. Benchmark studies are carried out prior to actual design in order to determine whether the numerical modelling can be performed reliably. Generally, a benchmark case is selected considering structural similarities. Apart from geometric similiarities, it is important to consider whether there is publicly available data. Following this, the results of regenerated benchmark case is compared with the original
\end{abstract}

\footnotetext{
*Elif OĞUZ, elifoguz@metu.edu.tr, https://orcid.org/0000-0003-3574-9436
} 
benchmark study. Since software or open-source code used for the study includes some theoretical assumptions as well as a number of simplifications, usually, researchers prefer to use comparison using different numerical tools. In this study, a cyclinder was modelled using WAMIT software (which was developed by MIT's researchers and used commonly in hydrodynamic analysis of offshore wind systems) and NEMOH (which was developed by Nantes laboratory researchers) and the benefits and the drawbacks of both software was discussed.

Keywords: Hydrodynamics, numerical modeling, open-source code.

\section{Giriș}

Son yıllarda karada kurulu rüzgar santrallerinin sayısında önemli oranda artış görülmektedir. Ancak, bu sistemlerin kuş yaşamını olumsuz etkileyip kuş ölümlerine sebep olduğu görülmüştür. Ayrıca yaşam alanlarında gürültü, gölge ve benzeri istenmeyen görsel "etkiler yaratması, enerji sektörünü başka alternatifleri araştırmaya yönlendirmiştir. Karada kurulu olanlarla kıyaslandığında açık deniz rüzgar türbinlerinin yüksek ve sürekli rüzgar hızı, yaşam alanları üzerindeki düşük görsel ve işitsel etkiler vb. avantajları göz önüne alındığından teknolojik gelişmeler o yönde ilerlemiştir [1]. Rüzgardan elektrik üretme fikrinin açık denizde ilk uygulaması 1991 yılında Danimarka'da Vindeby Rüzgar santrali ile gerçekleşmiştir [2]. Rüzgar türbininin açık denize taşınabilmesi için iki yol vardır. Birinci yol tekil kazık temel vb. sabit yapıları kullanmak, ikinci yol ise yüzer platformlardan yararlanmaktır. Bu ikisi arasındaki en önemli fark uygulama bölgesi olup, deniz derinliği burada en belirleyici faktör olarak bilinmektedir. Günümüze kadar edinilen deneyimler, sabit temelli uygulamaların 40 metre su derinliğine kadar hem teknik, hem maliyet bakımından uygun olduğunu göstermektedir [3]. Açıkdeniz rüzgar türbini için deniz tabanına tekil kazık gibi temellerle sabitlenenyapılar her ne kadar Birleşik Krallık (UK), Almanya ve Danimarka gibi ülkelerde her geçen gün yaygınlaşsa da bu yapılar, yukarıda da belirtildiği gibi, su derinliği ile kısıtlanmaktadır [4,5]. Aniden derinleşen ve dik kıta sahanlığına sahip birçok ülke için sabit temelli açıkdeniz rüzgar türbinleri ugulanabilir değildir. Ayrıca, su derinliğinin 50 metrenin üzerinde olması halinde bu yapılar çok pahalıya mal olmakta ve uygulanabilir olmaktan epey uzaklaşmaktadır. Bu sebeplerden ötürü, son yıllarda yatırımcıların yüzer açıkdeniz rüzgar türbinlerine olan ilgisi ve beraberinde bu konuda yapılan araştırma geliştirme faaliyetleri ciddi oranda artış göstermektedir.

Genelde, karada karşımıza çıkan bina ve benzeri engeller yüzey pürüzlülüğünü arttırarak elektriğe dönüştürülecek rüzgar enerji miktarını azaltmaktadır. Açıkdenizde yüzey sürtünmelerinin karaya nazaran çok az olması, rüzgar hızının açıkdenizde yüksek olmasına sebep olur ki; bu da yenilenebilir enerji sistemlerinin verimliliğini arttırır [6]. Rüzgardan elde edilecek enerji miktarı rüzgar hızının küpü ile orantılıdır. Bu sebeple kıyıdan ne kadar açıkdenize gidersek o kadar fazla enerji üretme imkanımız olmaktadır. Ancak kıyıdan olan mesafenin gerektiğinden fazla olması ise bakım-onarım maliyetlerini arttıracaktır.

$\mathrm{Bu}$ sistemler hayata geçmeden evvel birçok mühendislik yapısında olduğu gibi önce sayısal olarak modellenmekte, ardından yapının fiziksel model performansı laboratuvar ortamında incelenmektedir. Hatta bazı durumlarda kurulumdan önce bir pilot bölge seçilip, yakın kıyıda bir süre sistemin performansı incelenmektedir. Deneysel çalışma 
için her zaman laboratuvar olanakları uygun olmayabilir. Ayrıca araştırmacılar sayısal modellemeden laboratuvar ortamındaki fiziksel model testlerine kıyasla çok daha kısa sürede sonuç aldıkları için sayısal modellemelerin güvenilirliğinin gösterilmesi büyük önem taşır. Sıralanan sebeplerden ötürü açıkdeniz rüzgar türbinlerinin gerçek deniz koşullarındaki davranışlarının sayısal olarak modellemesinde kullanılan teknikler bu sektörün gelişimi için kritik bir öneme sahiptir. Sınırlı eleman yöntemi yenilenebilir enerji sistemlerinin sayısal modellemesinde ve denizcilik sektöründe belki de en yaygın kullanilan metotlardan biridir. Potansiyel teorinin lineer tabiatı sebebiyle her ne kadar kısıtlansa da, sayısal çözümlemeler için gerekli simülasyon süresi, hesaplamalı akışkanlar dinamiği gibi diğer sayısal metotlara kıyasla çok kısadır. Bu sebeple sınırlı eleman yönteminin yenilenebilir enerji sistemleri geliştirilirken özellikle tasarımın ilk aşamalarında sıklıkla tercih edildiği görülmektedir [7,8].

$\mathrm{Bu}$ tip yapıların gerçek deniz koşullarındaki davranışlarının sayısal modellemeleri yapılırken yapının hidro, aero, elastik analizlerini entegre eden açık kaynaklı kodlar kullanılır. Bunlardan en yaygın olarak kullanılanı, Amerika Ulusal Yenilenebilir Enerji Laboratuvarı (National Renewable Energy Laboratory- NREL) araştırmacıları tarafından geliştirilen FAST (Fatique, Aerodynamics, Structures and Turbulence) açık kaynaklı kodudur. Bu kodun yaygın kullanılmasının en önemli sebebi gerekli validasyonlar için çok geniş araştırma ekibinin çalışıyor olması, bu açık kaynaklı kodun ücretsiz olması ve daha da önemlisi bu kod kullanılarak yapılmış birçok örneğin ulaşılır olmasıdır. Birçok mühendislik problemini çözmek için geliştirilmeye uygun olması bu tip açık kaynaklı kodların yaygın kullanılmasına sebebiyet vermektedir. Yenilenebilir enerji sistemlerinin doğası gereği çok disiplinli çalışılmaktadır. Genelde her disiplin, kendi uzmanlık alanına giren kısım için gerekli hassasiyeti göstermekte ve analizlerinin güvenilirliğini ispatlamak durumundadır.

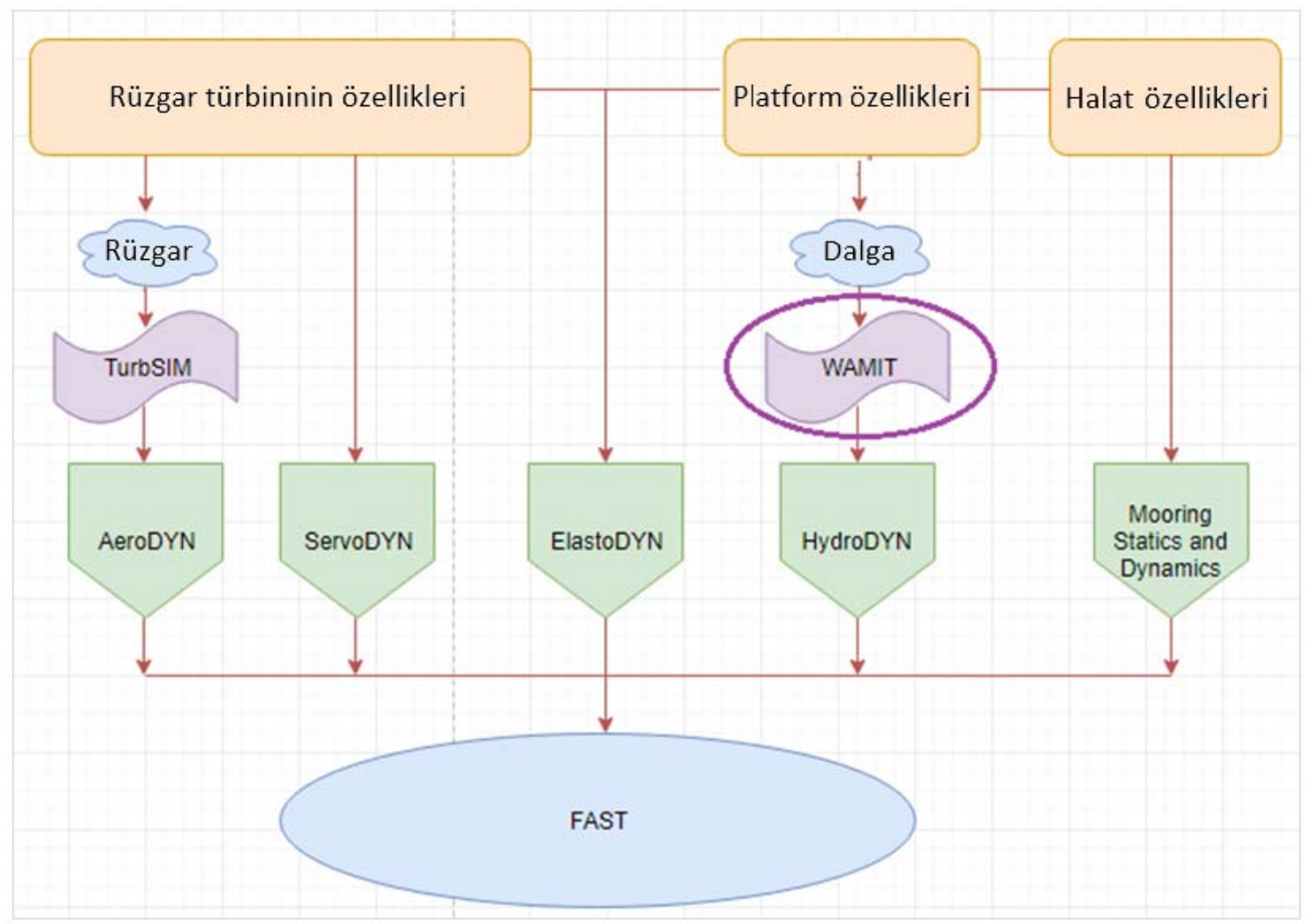

Şekil 1. FAST ve entegresyonu yapılan tüm programlar. 
Açıkdeniz yüzer rüzgar türbinlerinin suyun altında kalan kısımlarının hidrodinamik modellemesi yapılmalı, ardından da bu sonuçların diğer sonuçlarla entegresyonunu sağlayacak olan FAST açık kaynaklı koduna veri olarak aktarılması gerekmektedir. Şekil 1'de FAST programı ve çıktılarını girdi verisi olarak alacağı tüm alt programlar gösterilmiştir. WAMIT ile elde edilen hidrodinamik katsayıların direkt FAST'a aktarılıp entegresyonu mümkündür. Ancak WAMIT, lisansına her zaman belirli bir bedel ödenmesi gereken bir program olduğundan, bu çalışmada WAMIT ile hesaplanması istenen katsayıların belirlenmesinin NEMOH ile yapılması hedeflenmiş ve FAST'a uyumlu olup olmayacağı incelenmiştir.

$\mathrm{Bu}$ çalışmada iki hidrodinamik programın karşılaştırılması amaçlanmış olduğundan su altında kalan sistem basitleştirilmiştir. Programların analizi için gerekli parametrik çalışmaları arttırmak için 9m çapında silindir bir geometri seçilmiştir ve bu yapının hidrodinamik modellemesi iki ayrı program kullanılarak yapılmıştır. Kullanılan programlardan ilki akademik ve ticari amaçlarla kullanılabilen WAMIT yazılımıdır ki, kullanıcıların lisans için ücret ödemesi gerekmektedir. Hidrodinamik kuvvetlerin ve katsayıların hesabında alternatif olarak açık kaynaklı kod NEMOH kullanılmıştır ki, bu durumda kullanıcıların herhangi bir ücret ödemelerine gerek yoktur. Bu çalışmada her iki programdan alınan sonuçların, entegrasyonu sağlayacak olan programa (FAST) olan uyumu ve açık kaynaklı koddaki uyumsuzluğun nasıl giderileceği anlatılmıştır.

\section{Yöntem}

NEMOH, Ecole de Centrale de Nantes laboratuvarındaki araştırmacılar tarafından yaklaşık 30 sene önce geliştirilmesine rağmen halen birçok araştırma projesinde yaygın olarak kullanılmaktadır. Başlangıçta dalga enerji dönüştürücülerinin hidrodinamik davranışının analizini yapmak üzere hazırlanmış bir açık kaynaklı kod olsa da son yıllarda açıkdeniz yüzer yapılarının davranışını belirlemek için de tercih edilmektedir [8]. 2015 yılında 11.'si düzenlenen Avrupa Dalga ve Gelgit Enerji Konferansının bildiri kitabındaki bildiriler incelendiğinde hangi sınırlı eleman yönteminin ne sıklıkla kullanıldığ 1 görülmektedir. İlgili veriler aşağıda Tablo 1'de gösterilmiştir. Buradan anlaşılacağı üzere dalga enerji dönüştürücü sistemlerinin sayısal modellemelerinde en yaygın kulllanılan sınırlı eleman yöntemleri WAMIT ve NEMOH programlarıdır [9].

Tablo 1. Mevcut programlar ve özellikleri [7].

\begin{tabular}{|c|c|c|c|c|}
\hline Program & $\begin{array}{c}\text { Frekans } \\
\text { temelli analiz }\end{array}$ & $\begin{array}{c}\text { Zaman temelli } \\
\text { analiz }\end{array}$ & $\begin{array}{c}\text { Açık kaynaklı } \\
\text { kod }\end{array}$ & Kullanım (\%)* \\
\hline WAMIT & + & - & + & 80.5 \\
\hline NEMOH & + & - & - & 19.5 \\
\hline AQWA & + & - & - & 22.0 \\
\hline Aquaplus & + & - & - & 9.80 \\
\hline ACHIL3D & - & + & - & 4.90 \\
\hline WADAM & + & - & - & 7.30 \\
\hline
\end{tabular}

*[7]'de yayınlanan istatistiklere dayanır

NEMOH dalga enerji dönüştürücü sistemlerin hidrodinamik analizini yapmak üzere geliştirilen açık kaynaklı kod olduğundan araştırmacılar tarafından uzun yıllardır kullanılmasına rağmen literatür incelendiğinde yayınlanmış çalışmalara pek 
rastlanmamaktadır. Bunun bir sebebi, yenilenebilir enerji sistemi geliştirilirken patent kaygıları sebebiyle araştırmacıların mecburen göstermek durumunda kaldığ 1 özene, hassasiyete dayanır. Parisella ve Gourlay (2016) NEMOH ve WAMIT kullanarak kargo gemileri için yaptıkları hidrodinamik analizleri karşılaştırmıştır [9]. Ancak, bu açık kaynaklı kodun, başka hangi yenilenebilir enerji sistemlerinin analizinde ve hangi şartlarda kullanılabildiğine; kullanıldığında yaygın olarak tercih edilen WAMIT'e kıyasla ne gibi artılarının ve eksilerinin olduğuna literatürde rastlanmamıştır.

NEMOH dünyadaki ilk açık kaynaklı sınırlı eleman yöntemi kodu olarak bilinmektedir. Diğer sınırlı eleman yöntemlerinden farklı olarak, NEMOH lineer serbest yüzey sınır değer probleminin çözünürlüğü ile kütlenin sınır koşulu tanımını ayrıştırmaktadır. Bu özellik esnek yapılar, hidroelastisite ve alışılmadık serbestlik dereceleri için çözüm sağlanmasına olanak tanır.

$\mathrm{Bu}$ çalışma birinci derece kuvvetler ile sınırlandırılmıştır ve ikinci derece (sürükleme kuvvvetleri gibi non-lineer) etkiler hesaba katılmamıştır. Ayrıca adil bir karşılaştırma yapabilmek için, simülasyonlarda Rhino ile oluşturulan aynı geometri dosyası kullanılmıştır.

NEMOH ve WAMIT sırayla çalışan üç ana programdan oluşmaktadır : Ön işlemci, Çözümcü ve Son işlemci. Aşağıda Şekil 2'de NEMOH içinde çalışan programlar gösterilmiştir.

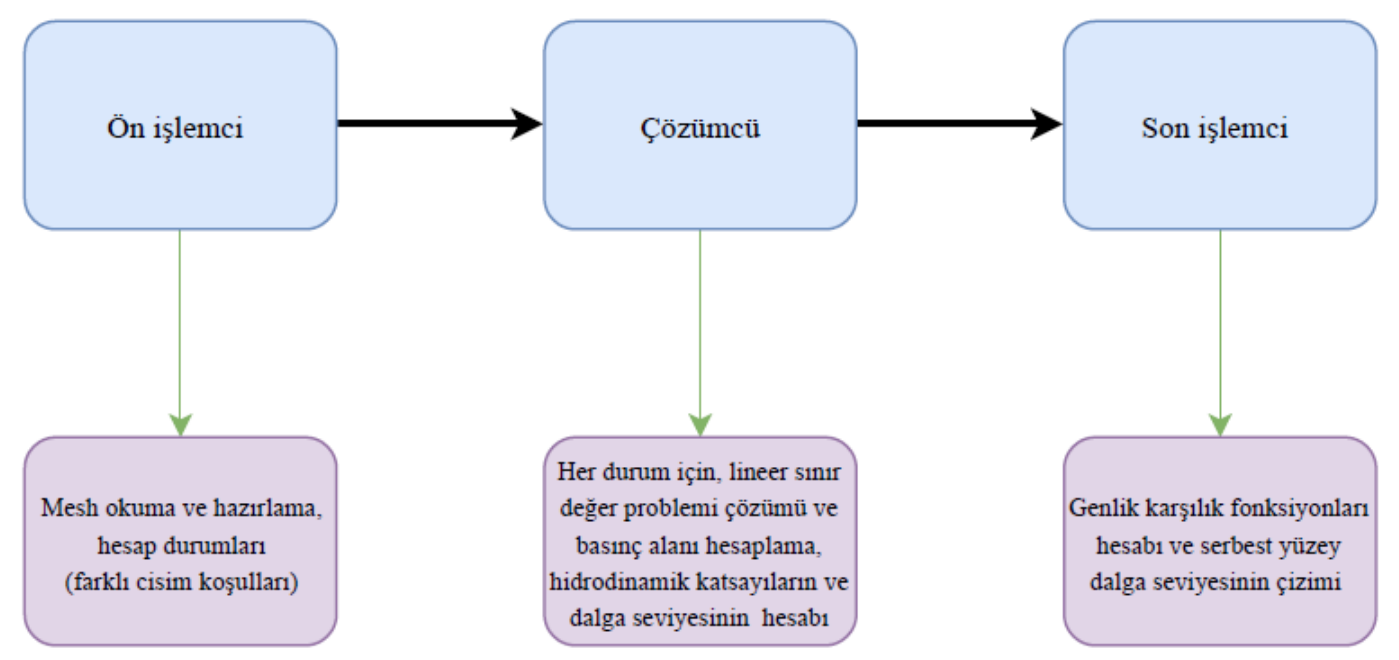

Şekil 2. NEMOH içinde çalışan programlar.

\section{3. İki yazılımın karşılaştırılması}

\section{1. Ön işlemci}

Ön işlemcide kullanıcı tarafından hazırlanan veri dosyaları program tarafindan okunur ve simülasyon için gerekli ağ oluşturulur. Genelde veriler çevre koşullarını tanıtmaya yarayan parametrelerdir; örneğin su derinliği, deniz suyu yoğunluğu, dalga periyodu ve yönü gibi. Ya da yapı durumlarına ait parametrelerdir; örneğin serbestlik derecesi, panel sayısı gibi. WAMIT boyutsuz sonuçlar verdiği için başlangıçta veri olarak yerçekimi, deniz suyunun yoğunluğu gibi parametrelerin tanımlanmasına ihtiyaç duyulmamaktadır. 


\subsubsection{Programın Kullanım Rahatlı̆̆}

WAMIT ile bir simülasyon çalıştırabilmek için birden fazla veri dosyası hazırlamak gerekmektedir. En basit bir simülasyon için genelde beş farklı veri dosyası hazırlanır. WAMIT'in en temel veri dosyaları ve kapsamları aşağıda Tablo 2'de özetlenmiş̧tir.

Tablo 2. WAMIT'in en temel veri dosyaları [10]

\begin{tabular}{|c|c|}
\hline Veri dosyasının ismi & Kapsamı \\
\hline config.wam & $\begin{array}{l}\begin{array}{l}\text { Çeşitli parametrelerin ve seçeneklerin tanımlandığ } 1 \text { veri } \\
\text { dosyasıdır. }\end{array} \\
\text {. }\end{array}$ \\
\hline SIM.cfg & $\begin{array}{l}\text { config.wam dosyasında tanımlanan parametrelerin neredeyse } \\
\text { hepsini kapsar. Farklı olarak, paralel hesaplamada ihtiyaç } \\
\text { duyulan parametreler bu veri dosyasında tanımlanır. }\end{array}$ \\
\hline SIM.pot & $\begin{array}{c}\text { Çevre koşullarının tanımlandığı veri dosyası. Ağ dosyasını } \\
\text { çağırır. Serbestlik derecesi ve yapının sabit koordinat düzlemi } \\
\text { burada tanımlanır. }\end{array}$ \\
\hline SIM.gdf & $\begin{array}{l}\text { Analizi yapılacak yapı geometrisinin 1slak yüzeyi burada } \\
\text { tanımlanır. }\end{array}$ \\
\hline SIM.frc & $\begin{array}{l}\text { Kütle matrisinin, ağırlık merkezinin tanımlandığı veri dosyasıdır. } \\
\text { Ayrıca o simülasyon sunucunda alınması istenen çıktıların } \\
\text { tanımlandığı veri dosyasıdır. }\end{array}$ \\
\hline
\end{tabular}

NEMOH'a baktığımızda benzer veri girişinin WAMIT'e kıyasla çok daha basit olduğunu söyleyebiliriz. Çünkü sadece bir tane veri dosyası (Nemoh.cal) ile simülasyon için gerekli olan tüm veriler çağrılabilmektedir. Ayrıca, ID.dat ve input.txt dosyaları çalışılan klasörün içine kopyalanmalıdır.

NEMOH, simülasyonları çalıştırmak için kullanıcılarına Matlab ve Fortran olmak üzere iki ayrı seçenek sunmaktadır. Dolayısıyla Fortran'a ya da Matlab'e hakim olan bir kullanıc NEMOH ile hidrodinamik modelleme yapabilmektedir. Ayrica Matlab ile NEMOH çalıştıranlar isterlerse önceden oluşturdukları ağ dosyasını aktarabilirler; isterlerse ağ oluşturmak için Matlab'te tanımlanan alt fonksiyon yardımıyla ağ oluşturabilmektedirler. Bu programlardan herhangi biri ile NEMOH'u çalıştırmak sonuç almak için yeterlidir.

\subsubsection{Kullanma kılavuzu ve Örnekler}

İki program arasındaki en büyük farklardan biri, geliştiren kurumlar tarafından sağlanan kullanma kılavuzu ve örneklerdir. WAMIT'in biri programın temelde dayandiğ 1 teorilerin ve kabullerin anlatıldığı çok kapsamlı teorik kılavuzu, diğeri ise tamamen programın nasıl kullanılacağını anlatan iki ayrı kullanma kılavuzu vardır. Diğer yandan NEMOH'un takip edilecek kullanma kılavuzu ise epey sınırlı olup, oldukça kısa tutulmuştur. Ayrıca WAMIT kılavuzunda kullanıcıların yararlanabileceği 25 adet örnekte tüm olasılıklar açıkça gösterilmiştir. Hatta kullanım kılavuzunun ek bölümünde bu örneklerin detaylı açıklamaları bulunmaktadır. NEMOH kullanıcılarının yararlanabileceği herhangi bir örnek bulunmamaktadır. Aradaki bu ciddi fark NEMOH'un yaygın olarak kullanımının önündeki bir engeli işaret etmektedir. 


\subsubsection{A Ăg oluşturma}

Bilindiği üzere, herhangi bir yapının sayısal olarak hidrodinamik analizinin yapılabilmesi için ilk aşamada tüm yüzeyler belirli hacimlere ayrılmalıdır, yani ağ oluşturulmalıdır. Aşağıdaki şekilde bu çalışmada modellenen silindir yapının geometrisi ve analizde kullanılan ağ görülmektedir. Karşılaştırma çalışması dikkate alınarak yapının yarıçapı $9 \mathrm{~m}$ olarak alınırken, yapının suyun altında kalan kısmı ise $47.86 \mathrm{~m}$ olarak alınmıştır. Sistemin toplam yer değiştirmesi $12171.1 \mathrm{~m}^{3}$ olarak verilmiştir. Analizler üzerinde herhangi bir etkisinin olup olmadığını anlamak için ilk etapta tam silindir ağ kullanılmıştır. Sonra çeyrek silindir için ağ oluşturup aradaki hassasiyet kontrol edilmiştir. Bu çalışmada yapıya dair detaylardan ve parametrik çalışmalardan çok, iki programın benzer ve farklı özellikleri üzerinde durulmuştur.
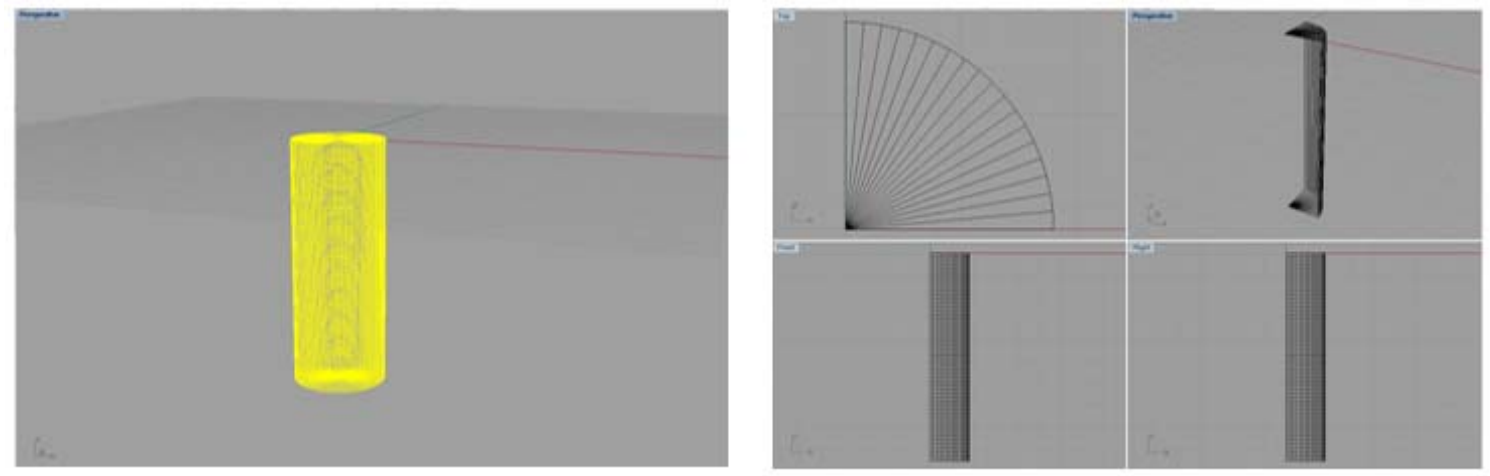

Şekil 3. Yap1 geometrisi ve kullanılan ağ.

WAMIT'in içinde herhangi bir ağ üretici olmadığından, analizi yapılacak yapı için başka bir yazılım ile ağ üretilip geometri dosyası çağrılmalıdır. NEMOH'da başka bir yazılım ile oluşturulan geometri dosyası kullanılabildiği gibi Matlab’teki alt fonksiyon ile ağ kolaylıkla oluşturulabilmektedir.

A $\breve{g}$ konusunda WAMIT ile NEMOH arasındaki en belirgin fark simetri düzlemidir. WAMIT iki simetri düzleminde ( $\mathrm{x} 0 \mathrm{z}$ ve $\mathrm{y} 0 \mathrm{z}$ ) hesaba izin verirken, $\mathrm{NEMOH}$ ise sadece bir simetri düzlemine $(\mathrm{x} 0 \mathrm{z})$ izin vermektedir ki bu da simülasyonun gerekli hesaplarını bazı durumlarda etkileyebilmektedir.

Sadece birkaç programda oluşturulan ağ dosyaları WAMIT'in kabul ettiği .gdf uzantılı veya NEMOH'un kabul ettiği .mar uzantılı olarak kaydedilebilmektedir. O yüzden WAMIT kullanıcılarının Multisurf, Rhino gibi programlarla gerekli dosyaları oluşturmaları gerekmektedir. Bu noktada NEMOH ile ağ dosyasının oluşturulabilmesi kullanıcıya bir avantaj sağlamaktadır. Ayrıca, NEMOH içerdiği bazı alt fonksiyonlar yardımıyla NEMOH'ta oluşturulmuş ağ dosyalarını WAMIT'in kabul ettiği formata .$g d f$ formuna ya da direkt okunabilen GDFmesh.m formuna dönüştürebilmektedir.

\section{2. Çözücü}

Bilindiği üzere, çözücü sınır değer problemini ön işlemcide tanımlanan her durum için çözer ve sonuçların olduğu çıktı dosyalarını oluşturur.

\subsection{Son işlemci}

Hidrodinamik katsayıların belirlenmesiyle bulunmuş olan hız potansiyeli, akışkanın her noktasında hidrodinamik basıncın bulunmasını sağlar. Cismin üzerine etkiyen lineer basıncın cisim cidarı boyunca integrali alınırsa hidrodinamik kuvvet bulunmuş olur. $\mathrm{Bu}$ 
bölümde silindir için elde edilen serbest su yüzey profili ve basınç dağılımları karşılaştırılmıştır. Elde edilen sonuçlar Techplot kullanılarak grafikler çizdirilmiştir. Ayrıca, NEMOH hem Matlab hem Fortran ile çalıştırılmış olup beklendiği üzere arada herhangi bir fark olmadığı görülmüştür. NEMOH'da farklı dalga periyotlarını kapsayacak şekilde çalışma yapmak WAMIT'e kıyasla çok daha uzun sürmüştür. Sonraki çalışmalarda buna dair iyileştirme NEMOH için yapılırsa simülasyon süresini kısaltmak mümkün olabilecektir..

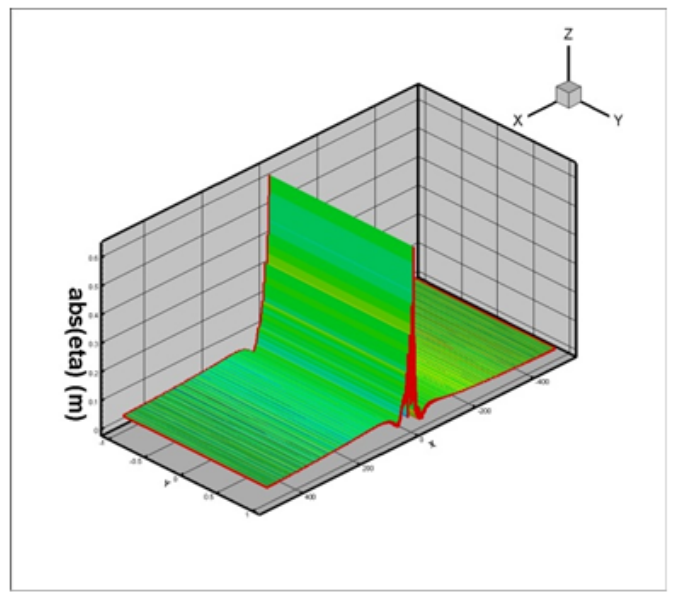

Serbest yüzey

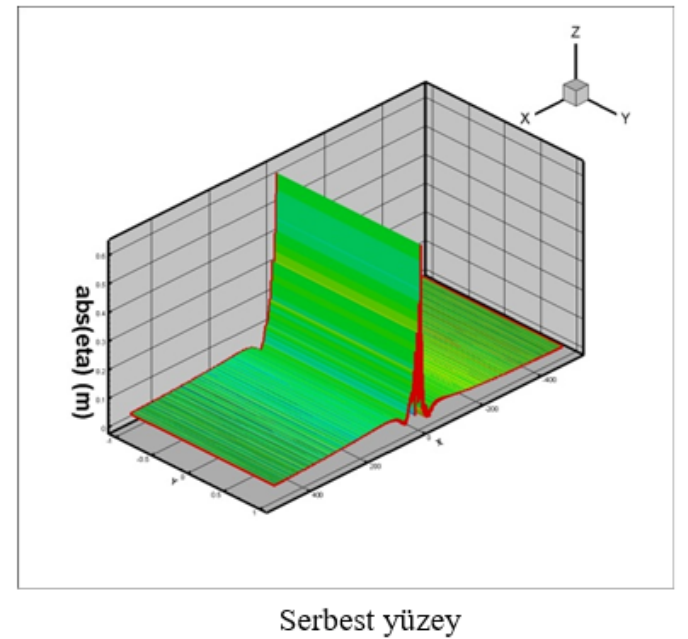

Serbest yüzey

Şekil 4. Serbest su yüzeyi profili.

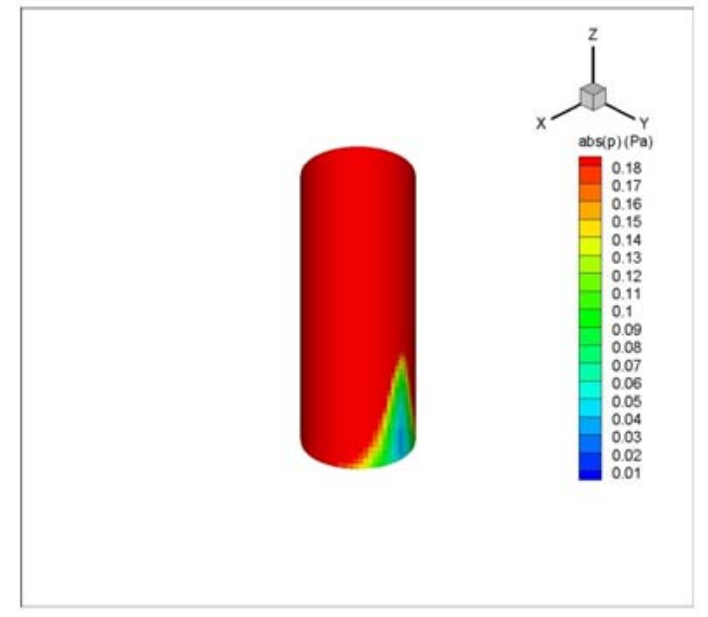

Basınç dağılımı

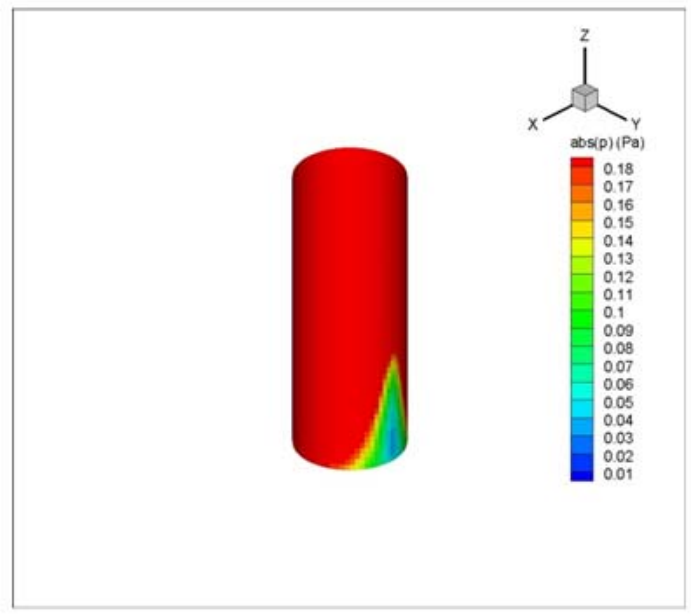

Basınç dağılımı

Şekil 5. Basınç dağılımı.

Son işlemci çözücüden gelen sonuçların sunumuyla ilgili olan bölümdür. Bu bağlamda, sınırlı eleman yöntemi çözücülerinin sonuçları için çok sayıda son işlemci mevcuttur. Ancak bazıları bu çalışmada karşılaştırılan her iki program için kullanılabilse de bazıları kullanılamamaktadır. Açıkdeniz yapısının sayısal modelinin entegrasyonunda FAST, Hydrodyn kullanmaktadır ki sadece WAMIT ile üretilen hidrodinamik katsayıları direkt veri olarak kabul edebilmektedir [11]. NEMOH sonuçları ise direkt veri olarak kulllanılamamaktadar. Ancak her iki yazılım da (WAMIT ve NEMOH) sonuçlarını text formatında verdiğinden, kullanıcıların yeterli vakti olması halinde sonuçları bir diğerinin okuyabildiği formata getirmek için ayrı bir kod yazılabilir. Her iki program ile 
yapının hidrodinamik katsayıları hesaplanmıştır. Ancak sonuçlar aynı formda olmadığından burada gösterilememektedir. Sonuçların Hydrodyn'in de kabul edeceği forma getirilmesi gelecekteki çalışmalar için çok faydalı olacaktır.

Parametrik çalışma avantajı ile hem farklı programlar karşılaştırılmış, hem de her birinin hassasiyeti incelenmiştir. Açık kaynaklı kodun avantajı, elde edilen hidrodinamik katsayıların Hydrodyn'in kabul edeceği forma getirilmesi ve böylece açıkdeniz yapılarının hidrodinamik performansının analizinde kolaylık sağlayacak olmasıdır. NEMOH ve WAMIT'in avantajları ve dezavantajları aşağıdaki tabloda siralanmıștır.

Tablo 3. WAMIT ve NEMOH karşılaştırılması.

\begin{tabular}{|c|c|c|c|}
\hline \multicolumn{2}{|c|}{ WAMIT } & \multicolumn{2}{|c|}{ NEMOH } \\
\hline Avantajlar & Dezavantajlar & Avantajlar & Dezavantajlar \\
\hline $\begin{array}{l}\text { Aynı simülasyonda } \\
\text { geniş bir frekans } \\
\text { aralığı ve farklı } \\
\text { dalga yönü için } \\
\text { analiz yapılabiliyor } \\
{[10]}\end{array}$ & $\begin{array}{l}\text { Lisanslı ücretli olan } \\
\text { bir program }\end{array}$ & Açık kaynaklı kod & $\begin{array}{l}\text { Girdi dosyaları } \\
\text { farklı dalga } \\
\text { freakansları veya } \\
\text { farklı dalga yönleri } \\
\text { için } \\
\text { geliştirilmelidir. Ya } \\
\text { da farklı dalga } \\
\text { yönleri için ayrı } \\
\text { ayrı çalıştırılmalıdır } \\
\text { ki bu da zaman } \\
\text { alıcıdır. }\end{array}$ \\
\hline $\begin{array}{l}\text { Sonuçları direkt } \\
\text { FAST yazılımında } \\
\text { kullanılabiliyor. }\end{array}$ & & $\begin{array}{l}\text { Görsel sonuçlar } \\
\text { Techplot yardımıyla } \\
\text { çizilebilir. }\end{array}$ & $\begin{array}{l}\text { Sonuçları direkt } \\
\text { FAST'da } \\
\text { kullanılamaz. }\end{array}$ \\
\hline $\begin{array}{l}\text { Validasyon başarıll } \\
\text { şekilde yapılabilir. }\end{array}$ & & & $\begin{array}{l}\text { Fortran ve Matlab } \\
\text { kullanılarak } \\
\text { çalıştırılsa da aynı } \\
\text { formda sonuç } \\
\text { vermediğinden } \\
\text { FAST yazılımında } \\
\text { girdi olarak } \\
\text { kullanılması için } \\
\text { yeni kod } \\
\text { yazılmasına ihtiyaç } \\
\text { vardır. }\end{array}$ \\
\hline
\end{tabular}

\section{Sonuç ve öneriler}

Silindirin hidrodinamik analizinden elde edilen grafikler sonucunda, kullanılan açık kaynaklı kod sonuçlarının yazılım sonuçları ile uyum gösterdiği görülmektedir. Bu çalışma ile daire kesitli yüzer cismin hem hidrodinamik katsayıları hem de radyasyon ve difraksiyon katsayıları elde edilmiştir. Sonuç olarak bu çalışmada ticari bir yazılım ile açık kaynaklı kodun karşılaştırılması ve açıkdeniz yüzer sistemlerin hidrodinamik performansının belirlenmesinde kullanılan FAST ile uyumlu çalışıp çalışmayacağ 
tartışılmıştır. NEMOH gibi açık kaynaklı kodların çıktılarının başka bir programda girdi olarak kullanılması için bazı kodlar yazılıp, gerekli düzenlemelerin yapılması gerekmektedir. NEMOH hem Fortran, hem Matlab ile çalıştırılabildiğinden kullanıcılara esneklik sağlamaktadır. Bu sebeple, Fortran'da yazılmış olan FAST ile uyumlu çalışabilmesi için bahsedilen kod hazırlığı yakın gelecekte yapılması planlanan bir çalışmadır.

\section{Teșekkür}

Bu çalışmada kullanılan WAMIT programı yazarın Strathclyde Üniversitesi’nde çalıştığı dönemde lisanslı olarak kullanılmıştır, yazar Strathclyde Üniversitesi'ne teşekkür eder.

\section{Kaynaklar}

[1] Bachynski, E.E., Design and Dynamic Analysis of Tension Leg Platform Wind Turbines, Doctoral Theses at NTNU, $2014: 86$.

[2] Leite, O.B., Review of Design Procedures for Monopile Offshore Wind Structures, Thesis of Master in Science, University of Porto Department of Civil Engineering, 2015.

[3] Oh, K.Y., Nam, W., Ryu, M.S., Kim, J.Y., Epureanu, B.I., A review of foundations of offshore wind energy convertors: Current status and future perspectives, Renewable and Sustainability Energy Reviews, 88, 16-36, (2918).

[4] O'Kelly, B.C., Arshad, M., Offshore wind turbine foundations-analysis and design, Offshore Wind Farms, 589-610, (2016).

[5] Wu, X., Hu, Y.,Li, Y., Yang, J., Duan, L., Wang, T., Adcock, T., Jiang, Z., Gao, Z., Lin, Z., Borthwick, A., Liao, S., Foundations offshore wind turbines: A review, Renewable and Sustainability Energy Reviews, 104, 379-393, (2019).

[6] Henderson, A.R., Morgan, C.S., Smith, B., Sorensen, H.C., Barthelmie, R.J. \& Boemans, B., Offshore Wind Enegy in Europe, A Review of the State-of-theArt, Wind Energy, 6, 35-52, (2003).

[7] Babarit, A., Delhommeau, G., Theoretical and numerical aspects of the open source BEM solver NEMOH, Proceedings of the $11^{\text {th }}$ European Wave and Tidal Energy Conference, Nantes (2015).

[8] Day, A.H., Babarit, A., Fontaine, A., He, Y.P., Kraskowski, M., Murai, M., Penesis, I., Salvatore, F., Shin, H.K., Hydrodynamic modelling of marine renewable energy devices : A state of the art review, Ocean Engineering, 108, 46-69, (2015)

[9] Parisella, G., Gourlay, T., Comparison of open-source code nemoh with wamit for cargo ship motions in shallow water, Technical Report, 23, Centre for Marine Science and Technology, Curtin University, (2016).

[10] Lee, C.H., Newman, J.N., WAMIT User Manual, WAMIT, Inc.:Chestnut Hill, MA, (2006).

[11] Jonkman, J.M., Buhl, M.L., FAST's user's guide. NREL/EL-500-38230. NREL: Golden, CO, (2005). 